ERRATUM

\title{
Correction: Diagnostic and therapeutic aspects of recurrent renal stone disease
}

\author{
Anthony Meyers, Natalie Whalley, Maria Martins \\ University of the Witwatersrand, Johannesburg, South Africa. \\ In Table 3 of the original publication of this article [ 1 ], the \\ citrate excretion in white subjects is given as 1.39(0.92), \\ which is incorrect. The correct value is $2.39(0.92)$.
}

\section{REFERENCE}

I. Meyers A, Whalley N, Martins M. Diagnostic and therapeutic aspects of recurrent renal stone disease. Afr J Nephrol. 1998; $2(1): 12-17$ 